\title{
PENGARUH KEPUASAN KERJA, KOMITMEN ORGANISASIONAL, MOTIVASI TERHADAP KINERJA MELALUI \\ ORGANIZATIONAL CITIZENSHIP BEHAVIOR (OCB) PADA KARYAWAN SPBU 4452212 BREBES
}

\author{
Muklis Ali Sobirin dan Maufur \\ SPBU Klampok dan Universitas Pancasakti Tegal \\ dr.Maufur@Gail.Com
}

\begin{abstract}
The purpose of this research to 1 ) analyze the influence of motivation of the performance of officers from Tegal city 2 ) analyze the influence of discipline work on performance officers from Tegal city 3 ) analyze the influence of motivation and discipline work on performance officers from Tegal .Respondents in this research as many as 84 people. These respondents is officers from tegal city. The necessary data collected to technique the questionnaire, literature study, observation and interview .Data analysis used in this research was descriptive analysis, test the assumption classical, regression analysis multiple, the testing of hypotheses and analysis the coefficients determination. The research can be concluded that is the positive and significant motivation to the performance of officers from tegal city. This is evidenced from the test hypothesis in partial obtained value significance of 0,011 which is smaller than 0.05 . The results of research suggests that is the positive and significant discipline work of the performance of the officers from tegal city. This is evidenced from the test hypothesis in partial obtained value significance of 0,000 which is smaller than 0.05 .The results of research suggests that is the positive and significant of the incentives and discipline work together to the performance of officers from tegal city. This is evidenced from the test hypothesis simultaneously obtained value significance (test anova $f$ ) of 0,000 which is smaller than 0.05 .
\end{abstract}

Keyword: motivation, discipline, performance

\section{PENDAHULUAN}

Fokus utama manajer dalam meningkatkan efektifitas perusahaan adalah perilaku sumber daya manusia (SDM) dalam bekerja. Efektifitas suatu perusahaan dapat dilihat dari interaksi kerja pada tingkat individual, kelompok, dan sistem-sistem organisasi yang menghasilkan output manusia yang memiliki tingkat absensi yang rendah, perputaran karyawan yang rendah, minimnya perilaku menyimpang dalam organisasi, tercapainya kepuasan kerja, memiliki komitmen terhadap perusahaan dan juga Organizational Citizenship Behavior (OCB) (Robbins \& Judge, 2008:31).

Karyawan merupakan aset perusahaan yang sangat berharga yang harus dikelola dengan baik oleh perusahaan agar dapat memberikan kontribusi yang optimal. Salah satu hal yang harus menjadi perhatian utama perusahaan adalah kepuasan kerja para karyawannya, karena karyawan yang dalam bekerja mereka tidak merasakan ke- 
nyamanan, kurang dihargai, tidak bisa mengembangkan segala potensi yang mereka miliki, maka secara otomatis karyawan tidak dapat fokus dan berkonsentrasi secara penuh terhadap pekerjaannya. Kepuasan kerja pegawai menurut Hariadja (2002:291) dapat dilihat bahwa "pekerjaan tidak hanya sekedar melakukan pekerjaan, tetapi terkait juga dengan aspek lain seperti melakukan interaksi dengan teman sekerja, atasan, mengikuti aturan - aturan dan lingkungan kerja tertentu yang seringkali tidak memadai atau kurang disukai."

Kepuasan kerja pada dasarnya merupakan hal yang bersifat individual, setiap individual memiliki tingkat kepuasan kerja yang berbeda-beda sesuai dengan keinginan dan sistem nilai yang dianutnya. (Handoko, 2000:192). Semakin banyak aspek dalam pekerjaannya yang sesuai dengan keinginan dan sistem nilai yang dianut individu, semakin tinggi tingkat kepuasan yang didapat. Demikian pula sebaliknya, semakin banyak aspek dalam pekerjaannya yang tidak sesuai dengan keinginan dan sistem nilai yang dianut individu, semakin rendah tingkat kepuasan yang didapat. Kepuasan kerja adalah keadaan emosional yang menyenangkan dengan bagaimana para pekerja memandang pekerjaan mereka.

Aspek-aspek yang dapat membentuk kepuasan kerja karyawan antara lain: faktor individual (umur, jenis kelamin, sikap pribadi terhadap pekerjaan), faktor hubungan antar karyawan (hubungan antar manajer dan karyawan, hubungan sosial antara sesama karyawan, sugesti dari teman sekerja, faktor fisik dan kondisi tempat kerja, emosi dan situasi kerja) faktor eksternal (keadaan keluarga, rekreasi, pendidikan). Aspek tersebut memberikan motivasi agar kepuasan kerja tercapai bagi karyawan. Dan yang berkewajiban memenuhi tercapainya kepuasan kerja tersebut adalah setiap pimpinan perusahaan, karena kepuasan kerja merupakan faktor yang diyakini dapat memotivasi semangat kerja karyawan agar karyawan dapat memberikan hasil yang terbaik bagi perusahaan sehingga kinerja perusahaan dapat ditingkatkan.

Selain itu kepuasan kerja juga mempunyai arti penting untuk aktualisasi diri karyawan. Karyawan yang tidak mendapatkan kepuasan kerja tidak akan mencapai kematangan psikologis. Karyawan yang mendapatkan kepuasan kerja yang baik biasanya mempunyai catatan kehadiran, perputaran kerja dan prestasi kerja yang baik dibandingkan dengan karyawan yang tidak mendapatkan kepuasan kerja. Kepuasan kerja memiliki arti yang sangat penting untuk memberikan situasi yang kondusif di lingkungan perusahaan.

Gomes (2003:171) mendifinisikan motivasi sebagai perilaku yang ditujukan pada sasaran. Motivasi berkaitan dengan tingkat usaha yang dilakukan oleh seseorang dalam mengejar suatu tujuan dan berkaitan erat dengan kepuasan pekerja dan performansi pekerjaan.

Komitmen adalah kemampuan dan kemauan untuk menyelaraskan perilaku pribadi dengan kebutuhan, prioritas, dan tujuan organisasi. Hal ini mencakup cara-cara mengembangkan tujuan atau memenuhi kebutuhan organisasi yang intinya mendahulukan misi organisasi dari pada kepentingan pribadi. Definisi komitmen organisasional ini menarik, dikarenakan yang dilihat adalah sebuah keadaan psikologi karyawan untuk tetap bertahan dalam organisasi. Beberapa organisasi memasukkan unsur komitmen sebagai salah satu syarat untuk memegang suatu jabatan atau posisi tertentu dalam kualifikasi lowongan pekerjaan. Hanya saja banyak pengusaha maupun pegawai 
yang masih belum memahami arti komitmen yang sebenarnya. Padahal pemahaman tersebut sangatlah penting agar tercipta kondisi kerja yang kondusif sehingga perusahaan dapat berjalan secara efisien dan efektif.

Komitmen organisasi mencerminkan bagaimana seorang individu mengidentifikasikan dirinya dengan organisasi dan terikat dengan tujuantujuannya. Para manajer disarankan untuk meningkatkan kepuasan kerja dengan tujuan untuk mendapatkan tingkat komitmen yang lebih tinggi. Selanjutnya, komitmen yang lebih tinggi dapat mempermudah terwujudnya produktivitas yang lebih tinggi.

Sebagai makhluk sosial, manusia mempunyai kemampuan untuk memiliki empati kepada orang lain dan lingkungannya dan menyelaraskan nilai-nilai yang dianutnya. Dengan nilai-nilai yang dimiliki lingkungannya untuk menjaga dan meningkatkan interaksi sosial yang lebih baik. Terlebih lagi, untuk melakukan segala sesuatu yang baik manusia tidak selalu digerakkan oleh hal-hal yang menguntungkan dirinya, misalnya seseorang mau membantu orang lain jika ada imbalan tertentu.

$O C B$ ini memang belum begitu dikenal, namun pada dasarnya pegawai dalam suatu perusahaan atau organisasi kadang-kadang sudah menerapkan $O C B$ dalam bekerja. Salah satu sikap strategik dalam divisi SDM adalah mengembangkan Organizational Citizenship Behavior $(O C B)$ dalam organisasi. $O C B$ ini tercermin melalui perilaku suka menolong orang lain, menjadi volunteer untuk tugas-tugas ekstra, patuh terhadap aturan-aturan dan prosedur-prosedur di tempat kerja. Perilaku ini menggambarkan nilai tambah karyawan yang merupakan salah satu bentuk perilaku prososial, yaitu perilaku sosial yang positif, konstruktif dan membantu.
Organ dalam artikel Gunawan (2011) mendefinisikan $O C B$ sebagai perilaku individual yang bersifat bebas (discretionary), yang tidak secara langsung dan eksplisit mendapat penghargaan dari sistem imbalan formal, dan yang secara keseluruhan mendorong keefektifan fungsi-fungsi organisasi. Bersifat bebas dan sukarela, karena perilaku tersebut tidak tercantum dalam deskripsi jabatan, yang secara jelas dituntut berdasarkan kontrak dengan organisasi; melainkan sebagai pilihan personal.

$$
\text { Spector dalam jurnal Nasir }
$$
(2011) mendefinisikan $O C B$ sebagai perilaku di luar persyaratan formal pekerjaan yang memberikan keuntungan bagi organisasi. Karyawan yang menunjukkan perilaku tersebut memberi kontribusi positif terhadap organisasi melalui perilaku di luar uraian tugas, di samping karyawan tetap melaksanakan tanggung jawab sesuai pekerjaannya.

Kunci sukses pertumbuhan setiap organisasi adalah kemampuannya dalam merekrut, mengembangkan dan mempertahankan talenta sumber daya manusianya. SPBU 4452212 Brebes telah menetapkan sasarannya untuk menjadi perusahaan pilihan untuk berkarya dengan menjadi perusahaan yang menawarkan lingkungan kerja positif agar setiap individu dapat mengembangkan seluruh potensinya. SPBU 44.522.12 Brebes melaksanakan struktur organisasi yang memungkinkan sumber daya manusia berkualitas dan kompetitif sehingga mampu beradaptasi dengan kemajuan dan perkembangan ilmu dan teknologi untuk menghasilkan kerja dan pelayanan terbaik sesuai dengan yang diharapkan.

SPBU 44.522.12 yang beralamat di jalan raya Klampok, wanasari Brebes, yang bergerak dibidang perusahaan jasa dan seperti yang diketahui sudah mendapat perhatian dari konsumen seperti SPBU lain. 
Perilaku $O C B$ tidak dimiliki oleh setiap karyawan. Oleh karena itu, perilaku $O C B$ ini sangat didukung oleh kontribusi dari perusahaan. Untuk memunculkan $O C B$ pada karyawan tentunya karyawan harus merasa puas terlebih dahulu. Aspek-aspek kepuasan kerja yaitu pekerjaan itu sendiri, gaji, pengakuan, supervisi, kerja sama yang baik dengan rekan kerja, serta kesempatan untuk berkembang (Mathis and Jackson, Sopiah 2008:196). Apabila karyawan sudah merasa senang, puas, dan nyaman dalam bekerja. Maka akan memuculkan perilaku OCB. Contoh nyata perilaku Organization Citizenship Behavior dalam kehidupan sehari-hari misalnya salah satu karyawan telah menyelesaikan tugasnya, dan tidak ada lagi tugas yang ia kerjakan, lalu ia putuskan untuk menolong mengerjakan tugas karyawan lain dengan tujuan agar tugas yang dikerjakan dapat dengan cepat terselesaikan.

Melihat kondisi tersebut, munculnya $O C B$ menjadi hal yang positif bagi perusahaan, tak terkecuali di perusahaa. Diharapkan dapat berkembang dan tumbuh menjadi SPBU kepercayaan masyarakat yang dibangun dengan integritas, loyalitas dan kerja sama dari seluruh pemangku perusahaan.

Kinerja merupakan suatu fungsi dari motivasi dan kemampuan. Untuk menyelesaikan tugas atau pekerjaan seseorang sepatutnya memiliki derajat kesediaan dan tingkat kemampuan tertentu. Kesediaan dan keterampilan seseorang tidaklah cukup efektif untuk mengerjakan sesuatu tanpa pemahaman yang jelas tentang apa yang akan dikerjakan dan bagaimana mengerjakannya. Kinerja merupakan perilaku nyata yang ditampilkan setiap orang sebagai prestasi kerja yang dihasilkan oleh karyawan sesuai dengan perannya dalam perusahaan. Kinerja karyawan merupakan suatu hal yang sangat penting dalam upaya perusahaan untuk mencapai tujuannya.

Oleh karena itu dapat disimpulkan bahwa kinerja sumber daya manusia adalah prestasi kerja atau hasil kerja (output) baik kualitas maupun kuantitas yang dicapai sumber daya manusia persatuan periode waktu dalam melaksanakan tugas kerjanya sesuai dengan tanggungjawab yang diberikan kepadanya.

Dari definisi tersebut di atas, maka dapat disimpulkan bahwa kinerja kayawan berkaitan dengan mempunyai rasa tanggung jawab yang tinggi dalam mencapai visi dan misi perusahaan, ketepatan dan ketaatan waktu dalam menyelesaikan setiap pekerjaan, memiliki sifat kejujuran yang tinggi dalam bekerja, kecakapan karyawan dalam melaksanakan tugas dari pimpinan, tidak menyalahgunakan wewenang yang diberikan pimpinan serta karyawandapat melakukan proses kerja dengan baik dan sesuai dengan standar perusahaan dalam melaksanakan suatu tugas atau pekerjaan yang dibebankan kepadanya dengan mengarahkan sumber daya yang dimilikinya baik berupa kecakapan, keterampilan juga pengalaman dan kesungguhan hatinya hingga diperoleh hasil kerja yang maksimal.

Untuk melaksanakan tujuannya yaitu memberikan pelayanan yang terbaik bagi konsumen, membutuhkan sumber daya manusia dalam rangka mencapai tujuan organisasi. Tentu saja hal ini dapat tercapai apabila karyawan yang dimiliki perusahaan memiliki komitmen organisasional yang tinggi sehingga meningkatkan kinerja karyawan dan perusahaan.Komitmen organisasional yang dapat ditunjukan oleh karyawan seperti karyawan merasa senang bekerja dalam lingkungan SPBU, serta merasa memiliki tanggung jawab pekerjaan. 
Berdasarkan hasil observasi dan informasi, terdapat 2 jenis karyawan pada. Yaitu, karyawan kantor yang teridiri dari manager operasional, admin, dan kasir. Sedangkan, karyawan lapangan terdiri dari pengawas BBM, pengawas non BBM, operator SPBU, security dan cleaning service. Dalam melaksanakan pekerjaan sehari-harinya, karyawan lapangan tersebut langsung berhadapan dengan pelanggan. Untuk itu, karyawan lapangan harus dapat membuat pelanggan menjadi nyaman dalam menggunakan jasa layanan SPBU.

Mengingat sudah banyak terdapat SPBU asing yang menawarkan pelayanan serupa disertai dengan keunggulannya masing-masing. Sebagai contoh, bagi seorang operator dalam menjalankan tugasnya harus melakukan semua SOP yang telah ditetapkan, seorang cleaning service harus menjaga kebersihan fasilitas-fasilitas umum seperti WC dan Mushola, dan bagi security, harus menjaga keamanan SPBU agar pekerjaan berjalan lancar.

Maka, agar tidak kehilangan pelanggan setianya, dibutuhkan kinerja yang terbaik yang ditampilkan oleh karyawan lapangan dalam melayani pelanggan, kinerja yang ditampilkan oleh karyawan lapangan sangat dipengaruhi oleh komitmen organisasional yang dimiliki oleh karyawan lapangan tersebut.

Pada penelitian ini, peneliti mengambil objek pada SPBU 44.522.12, yang terletak di kawasan jalan raya Klampok, Wanasari Brebes. Alasan pemilihan SPBU ini dikarenakan memiliki tingkat penjualan yang amat tinggi dikarenakan banyak armada bus dewi sri yang mengisi di SPBU ini.Selain itu, jumlah karyawan yang dimiliki SPBU ini berjumlah 33 orang. SPBU ini mempunyai tiga macam jenis produk, yaitu Solar, Premium, dan Pertamax. Ditambah lagi, daerah SPBU ini yang strategis, yaitu berada pada pinggir jalan besar, jalan utama pantura sehingga tidak jarang akan terlihat antrean kendaraan yang akan mengisi BBM pada SPBU ini.

Berdasarkan kenyataan lapangan diatas yang peneliti dapatkan dari manager, untuk mencapai target penjualan SPBU maka setiap karyawan perlu untuk menunjukkan kinerja yang terbaik. Kinerja yang terbaik ini dapat terwujud apabila karyawan memiliki komitmen organisasional terhadap tempat ia bekerja. Jadi diharapkan SDM yang tidak hanya memiliki skill dan kualitas yang baik tetapi memiliki perilaku ekstra dimana salah satunya adalah $O C B$.

Berdasarkan latar belakang di atas, penulis tertarik untuk meneliti "Pengaruh Kepuasan Kerja, Komitmen Organisasional, Motivasi Terhadap Kinerja melalui Organizational Citizenship Behavior (OCB) Pada Karyawan SPBU 44.522.12 Brebes".

\section{METODE}

Jenis penelitian ini menggunakan observasional analitik dengan rancangan Cross Sectional, yaitu untuk mengetahui hubungan antara variabel kepuasan kerja,komitmen dengan $O C B$. Dengan penelitian ini dapat dibangun suatu teori yang dapat berfungsi untuk menjelaskan, meramal, memprediksi dan mengontrol suatu gejala. Penelitian ini bersifat Kuantitatif karena menggunakan data yang memerlukan perhitungan dan menggunakan analisa Kualitatif untuk mendeskripsikan data yang sudah diperoleh sehingga akan lebih jelas.Untuk mendapatkan Instrumen penelitian yang valid dan relaiabel harus terlebih dahulu dilakukan uji coba instrument yakni uji validitas dan relaibilitas dengan menggunakan rumus Product Moment dan Alpha Cronbach. Sedangkan alat analisis data dan interpretasi untuk penelitian 
yang ditujukan untuk menjawab pertanyaan-pertanyaan penelitian dalam rangka mengungkap fenomena social tertentu, Metode yang dipilih untuk menganalisis data harus sesuai dengan pola penelitian dan variable yang akan diteliti. Untuk menganalisis data digunakan The Structural Equation Modeling (SEM) dari paket software statistik
AMOS 19 dalam model dan pengkajian hipotesis. Model persamaan structural, Structural Equation Model (SEM) adalah sekumpulan teknik-teknik statistical yang memungkinkan pengujian sebuah rangkaian hubungan relatif "rumit" secara simultan (Ferdinand, 2011).

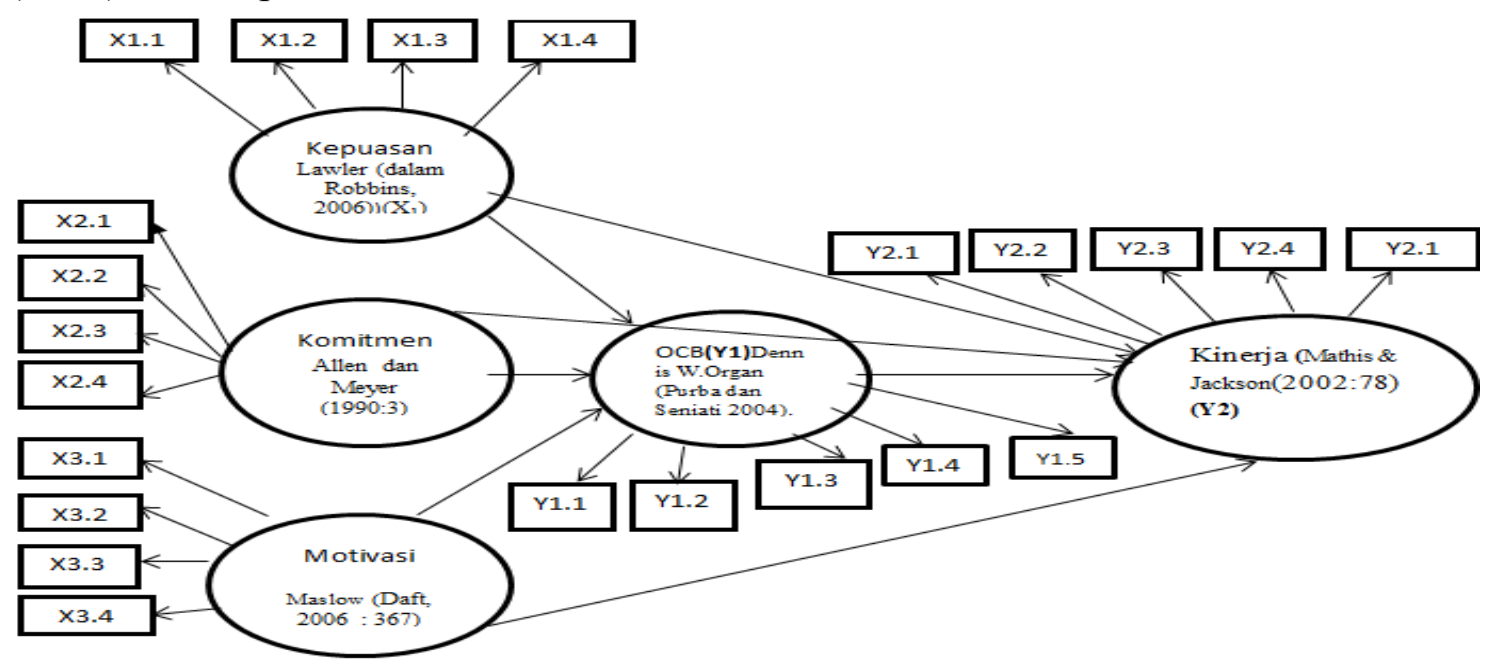

Gambar 1

Model Persamaan Struktural Penelitian

\section{HASIL DAN PEMBAHASAN}

\section{Analisis Asumsi Structural Equating Modeling (SEM)}

Untuk melakukan analisis inferensial dalam penelitian ini digunakan teknik Structural Equation Modeling (SEM). Dalam melakukan analisis dengan teknik Structural Equation Modeling (SEM), estimasi dilakukan secara bertahap, yaitu pertama, dengan melakukan teknik Confirmatory Factor Analysis. Analisis Faktor Konfirmatori (Confirmatory Factor Analysis) disebut sebagai teknik analisis faktor konfirmatori sebab pada tahap ini model akan mengkonfirmasi apakah variabel yang diamati dapat mencerminkan faktor yang dianalisis. Unidimensionalitas dari dimensi-dimensi itu diuji melalui confirmatory factor analysis yang hasil- nya seperti yang disajikan berikut ini.

\section{a. Analisis Konfirmatori Variabel Kepuasan $\left(\mathbf{X}_{1}\right)$}

Analisis konfirmatori variabel kepuasan dilakukan untuk mengkonfirmasi apakah indikator yang diamati dapat mencerminkan faktor yang dianalisis yaitu variabel kepuasan. Adapun hasil analisis konfirmatori yang dilakukan terhadap variabel kepuasan diuraikan di bawah ini: 


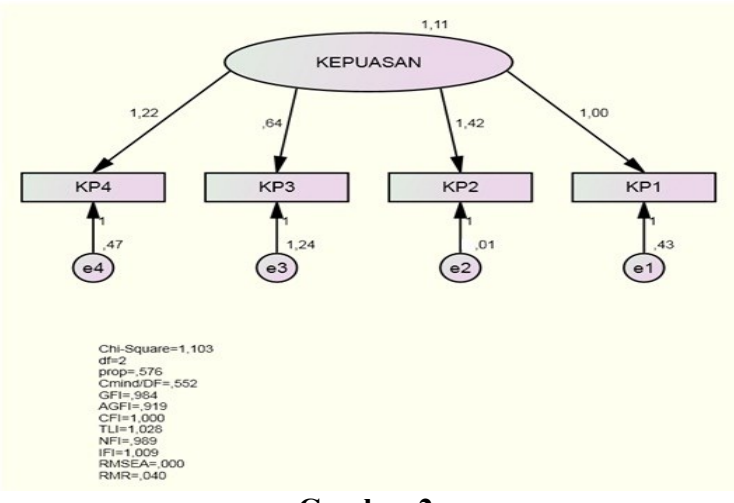

Gambar 2

Hasil Analisis Konfirmatori Variabel Kepuasan $\left(\mathbf{X}_{1}\right)$

Untuk melakukan analisis konfirmatori variabel kepuasan, uji dasar yang harus dilakukan yaitu dengan menguji kesesuaian model-Goodness of Fit Test, hasil pengujian kesesuaian model pada konfirmatori factor analisis disajikan dalam Tabel di bawah ini:

\section{Tabel 1}

Hasil Pengujian Kelayakan Variabel Kepuasan $\left(\mathrm{X}_{1}\right)$

\begin{tabular}{|l|c|c|c|}
\hline $\begin{array}{c}\text { Goodness of } \\
\text { Fit Indeks }\end{array}$ & $\begin{array}{c}\text { Cut off } \\
\text { Value }\end{array}$ & Hasil & Evaluasi Model \\
\hline Chi-Square & $<5,99$ & 13,952 & $\begin{array}{c}\text { Tidak } \\
\text { Memenuhi }\end{array}$ \\
\hline DF & $>0$ & 2 & Memenuhi \\
\hline Probability & $>0,05$ & 0,001 & $\begin{array}{c}\text { Tidak } \\
\text { Memenuhi }\end{array}$ \\
\hline RMSEA & $\leq 0,08$ & 0,432 & $\begin{array}{c}\text { Tidak } \\
\text { Memenuhi }\end{array}$ \\
\hline CMIN/DF & $<2$ & 6,960 & $\begin{array}{c}\text { Tidak } \\
\text { Memenuhi }\end{array}$ \\
\hline CFI & $\geq 0,90$ & 0,891 & \begin{tabular}{c} 
Memenuhi \\
\hline CMIN/DF
\end{tabular} \\
\hline TLI atau & $\geq 0,00$ & 0,852 & Memenuhi \\
\hline NNFI & $\geq 0,90$ & 0,672 & $\begin{array}{c}\text { Tidak } \\
\text { Memenuhi }\end{array}$ \\
\hline NFI & $\geq 0,90$ & 0,432 & $\begin{array}{c}\text { Tidak } \\
\text { Memenuhi }\end{array}$ \\
\hline IFI & & 0,895 & Memenuhi \\
\hline
\end{tabular}

Sumber: Data Primer Diolah, 2016

Dari Tabel di atas menunjukkan bahwa nilai Chi Square $=13,952$ dengan tingkat signifikansi sebesar 5,99 demikian pula dengan nilai kelayakan yang lain yang memenuhi kriteria fit sehingga dapat disimpulkan bahwa tidak terdapat perbedaan antara matriks kovarians sample dengan matriks kovarians populasi yang diestimasi diterima yang berarti model adalah fit. Sehingga secara keseluruhan model dapat diterima untuk memberikan konfirmasi yang cukup untuk dapat diterimanya hipotesis unidimensionalitas bahwa keempat indicator yang digunakan dapat mencerminkan variabel laten yang dianalisis yaitu variable kepuasan.

\section{b. Analisis Konfirmatori Variabel Komitmen $\left(\mathbf{X}_{2}\right)$}

Analisis konfirmatori variabel Komitmen dilakukan untuk mengkonfirmasi apakah indikator yang diamati dapat mencerminkan faktor yang dianalisis yaitu variabel Komitmen. Adapun hasil analisis konfirmatori yang dilakukan terhadap variabel Komitmen diuraikan di bawah ini:
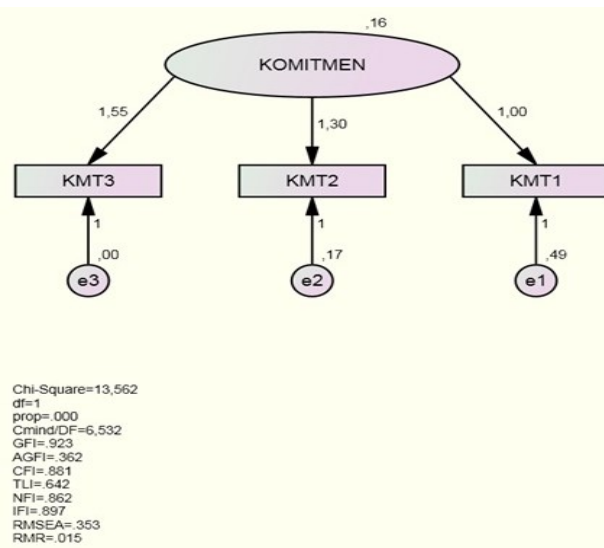

Gambar 3

Hasil Analisis Konfirmatori Variabel Komitmen $\left(\mathbf{X}_{2}\right)$

Untuk melakukan analisis konfirmatori variabel Komitmen, harus dilakukan pemenguji kesesuaian model-Goodness of Fit Test, hasil pengujian kesesuaian model pada konfirmatori factor analisis disajikan dalam Tabel di bawah ini:

Tabel 2

Hasil Pengujian Kelayakan

Variabel Komitmen $\left(\mathrm{X}_{2}\right)$

\begin{tabular}{|l|c|c|c|}
\hline $\begin{array}{c}\text { Goodness of } \\
\text { Fit Indeks }\end{array}$ & $\begin{array}{c}\text { Cut off } \\
\text { Value }\end{array}$ & Hasil & $\begin{array}{c}\text { Evaluasi } \\
\text { Model }\end{array}$ \\
\hline DF & $>0$ & 1 & Memenuhi \\
\hline Chi-Square & $<3,84$ & 13,550 & $\begin{array}{c}\text { Tidak } \\
\text { Memenuhi }\end{array}$ \\
\hline Probability & $>0,05$ & 0,000 & Memenuhi \\
\hline CMIN/DF & $<2$ & 6,532 & $\begin{array}{c}\text { Tidak } \\
\text { Memenuhi }\end{array}$ \\
\hline CFI & $\geq 0,90$ & 0,881 & Memenuhi \\
\hline TLI atau NNFI & $\geq 0,90$ & 0,642 & $\begin{array}{c}\text { Tidak } \\
\text { Memenuhi }\end{array}$ \\
\hline NFI & $\geq 0,90$ & 0,865 & Memenuhi \\
\hline IFI & $\geq 0,90$ & 0,897 & Memenuhi \\
\hline RMSEA & $\leq 0,08$ & 0,353 & $\begin{array}{c}\text { Tidak } \\
\text { Memenuhi }\end{array}$ \\
\hline
\end{tabular}

Sumber: Data Primer Diolah, 2016 
Dari Tabel di atas menunjukkan bahwa nilai Chi Square $=13,550$ dengan tingkat signifikansi sebesar 3,84 demikian pula dengan nilai kelayakan yang lain yang belum memenuhi kriteria fit sehingga dapat disimpulkan bahwa terdapat perbedaan antara matriks kovarians sample dengan matriks kovarians populasi yang diestimasi diterima yang berarti model adalah belum fit. Namun demikian perlu diketahui bahwa Chi Square sangat sensitive terhadap jumlah sampel (Ghozali, 2004). Oleh karena itu dicari ukuran model fit yang lain, yaitu CFI mendekati 0,90 yakni 0,881 . Sehingga secara keseluruhan model dapat diterima untuk memberikan konfirmasi yang cukup untuk dapat diterimanya hipotesis unidimensionalitas bahwa keempat indikator yang digunakan dapat mencerminkan variabel laten yang dianalisis yaitu variabel komitmen.

\section{c. Analisis Konfirmatori Variabel Motivasi $\left(\mathbf{X}_{3}\right)$}

Analisis konfirmatori variabel Motivasi dilakukan untuk mengkonfirmasi apakah indikator yang diamati dapat mencerminkan faktor yang dianalisis yaitu variabel kompetensi. Adapun hasil analisis konfirmatori yang dilakukan terhadap variabel kompetensi diuraikan di bawah ini:
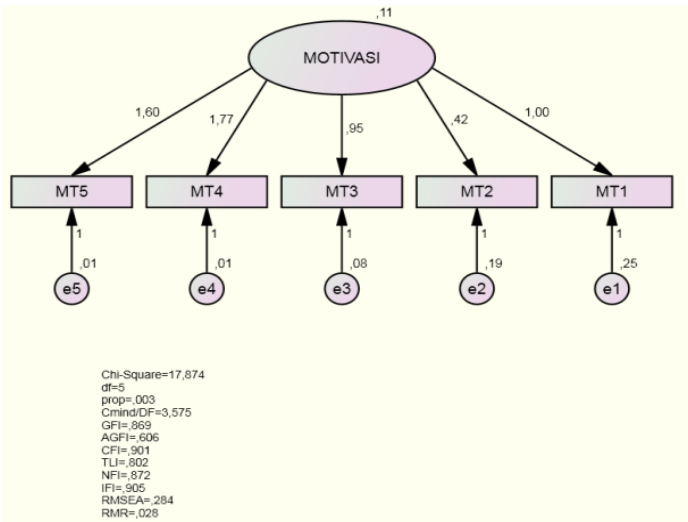

Gambar 4

Hasil Analisis Konfirmatori Variabel Motivasi $\left(\mathbf{X}_{3}\right)$
Untuk melakukan analisis konfirmatori variabel Motivasi, uji dasar yang harus dilakukan yaitu dengan menguji kesesuaian model-Goodness of Fit Test, hasil pengujian kesesuaian model pada konfirmatori factor analisis disajikan dalam Tabel di bawah ini:

Tabel 3

Hasil Pengujian Kelayakan Variabel Motivasi $\left(\mathrm{X}_{3}\right)$

\begin{tabular}{|l|l|c|c|}
\hline $\begin{array}{c}\text { Goodness of } \\
\text { Fit Indeks }\end{array}$ & $\begin{array}{c}\text { Cut off } \\
\text { Value }\end{array}$ & Hasil & $\begin{array}{c}\text { Evaluasi } \\
\text { Model }\end{array}$ \\
\hline DF & $>0$ & 5 & Memenuhi \\
\hline Chi-Square & $<11,07$ & 17,874 & $\begin{array}{c}\text { Tidak } \\
\text { Memenuhi }\end{array}$ \\
\hline Probability & $>0,05$ & 0,003 & $\begin{array}{c}\text { Tidak } \\
\text { Memenuhi }\end{array}$ \\
\hline CMIN/DF & $<2$ & 3,575 & $\begin{array}{c}\text { Tidak } \\
\text { Memenuhi }\end{array}$ \\
\hline CFI & $\geq 0,90$ & 0,901 & Memenuhi \\
\hline TLI atau NNFI & $\geq 0,90$ & 0,802 & Memenuhi \\
\hline NFI & $\geq 0,90$ & 0,872 & Memenuhi \\
\hline IFI & $\geq 0,90$ & 0,905 & Memenuhi \\
\hline RMSEA & $\leq 0,08$ & 0,284 & $\begin{array}{c}\text { Tidak } \\
\text { Memenuhi }\end{array}$ \\
\hline
\end{tabular}

Sumber: Data Primer Diolah, 2016

Dari Tabel di atas menunjukkan bahwa nilai Chi Square $=17,874$ dengan tingkat signifikansi sebesar 11,07 demikian pula dengan nilai kelayakan yang lain yang memenuhi kriteria belum fit sehingga dapat disimpulkan bahwa terdapat perbedaan antara matriks kovarians sample dengan matriks kovarians populasi yang diestimasi diterima yang berarti model adalah belum fit. Namun demikian perlu diketahui bahwa Chi Square sangat sensitive terhadap jumlah sampel (Ghozali, 2004). Oleh karena itu dicari ukuran model fit yang lain, yaitu CFI mendekati 0,90 yakni 0,901 . Sehingga secara keseluruhan model dapat diterima untuk memberikan konfirmasi yang cukup untuk dapat diterimanya hipotesis unidimensionalitas bahwa kelima indikator yang digunakan dapat mencerminkan variabel laten yang dianalisis yaitu variabel motivasi. 


\section{d. Analisis Konfirmatori Variabel $O C B(\mathrm{Y} 1)\left(\mathrm{Y}_{1}\right)$}

Analisis konfirmatori variabel $O C B$ dilakukan untuk mengkonfirmasi apakah indikator yang diamati dapat mencerminkan faktor yang dianalisis yaitu variabel $O C B$. Adapun hasil analisis konfirmatori yang dilakukan terhadap variabel $O C B$ diuraikan di bawah ini:
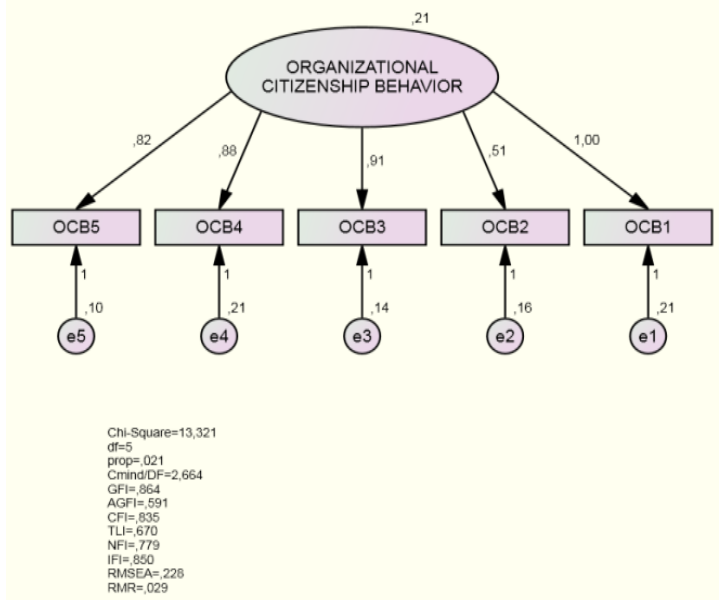

Gambar 5

Hasil Analisis Konfirmatori Variabel $O C B\left(\mathrm{Y}_{1}\right)$

Untuk melakukan analisis konfirmatori variabel $O C B$, uji dasar yang harus dilakukan yaitu dengan menguji kesesuaian model-Goodness of Fit Test, hasil pengujian kesesuaian model pada konfirmatori factor analisis disajikan dalam Tabel di bawah ini:

Tasil Pengujian Kelayakan
Variabel $\boldsymbol{O C B}\left(\mathbf{Y}_{\mathbf{1}}\right)$

Dari Tabel di atas menunjukkan bahwa nilai Chi Square $=13,321$ dengan tingkat signifikansi sebesar 11,07 demikian pula dengan nilai kelayakan yang lain yang belum memenuhi kriteria belum fit sehingga dapat disimpulkan bahwa terdapat perbedaan antara matriks kovarians sample dengan matriks kovarians populasi yang diestimasi diterima yang berarti model adalah belum belum fit. Sehingga secara keseluruhan model tidak dapat diterima untuk memberikan konfirmasi yang cukup untuk dapat diterimanya hipotesis unidimensionalitas bahwa kelima indikator yang digunakan dapat mencerminkan variabel laten yang dianalisis yaitu variabel $O C B$.

\section{e. Analisis Konfirmatori Variabel Kinerja Karyawan (Y2)}

Analisis konfirmatori variabel Kinerja Karyawan dilakukan untuk mengkonfirmasi apakah indikator yang diamati dapat mencerminkan faktor yang dianalisis yaitu variabel Kinerja Karyawan. Adapun hasil analisis konfirmatori yang dilakukan terhadap variabel Kinerja Karyawan diuraikan di bawah ini:

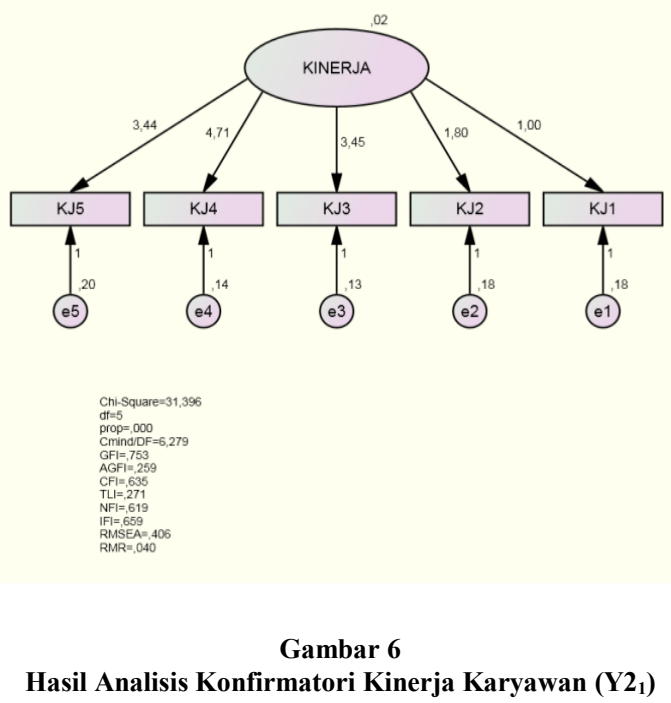


Untuk melakukan analisis konfirmatori variabel Kinerja Karyawan, uji dasar yang harus dilakukan yaitu dengan menguji kesesuaian model-Goodness of Fit Test, hasil pengujian kesesuaian model pada konfirmatori factor analisis disajikan dalam Tabel di bawah ini:

\begin{tabular}{|l|c|c|c|}
\hline $\begin{array}{c}\text { Goodness of } \\
\text { Fit Indeks }\end{array}$ & $\begin{array}{c}\text { Cut off } \\
\text { Value }\end{array}$ & Hasil & $\begin{array}{c}\text { Evaluasi } \\
\text { Model }\end{array}$ \\
\hline DF & $>0$ & 5 & Memenuhi \\
\hline Chi-Square & $<11,07$ & 31,396 & $\begin{array}{c}\text { Tidak } \\
\text { Memenuhi }\end{array}$ \\
\hline Probability & $>0,05$ & 0,000 & $\begin{array}{c}\text { Tidak } \\
\text { Memenuhi }\end{array}$ \\
\hline CMIN/DF & $<2$ & 6,279 & $\begin{array}{c}\text { Tidak } \\
\text { Memenuhi }\end{array}$ \\
\hline CFI & $\geq 0,90$ & 0,635 & $\begin{array}{c}\text { Tidak } \\
\text { Memenuhi }\end{array}$ \\
\hline TLI atau NNFI & $\geq 0,90$ & 0,271 & $\begin{array}{c}\text { Tidak } \\
\text { Memenuhi }\end{array}$ \\
\hline NFI & $\geq 0,90$ & 0,619 & $\begin{array}{c}\text { Tidak } \\
\text { Memenuhi }\end{array}$ \\
\hline IFI & $\geq 0,90$ & 0,659 & $\begin{array}{c}\text { Tidak } \\
\text { Memenuhi }\end{array}$ \\
\hline RMSEA & & 0,405 & $\begin{array}{c}\text { Tidak } \\
\text { Memenuhi }\end{array}$ \\
\hline
\end{tabular}

Dari Tabel di atas menunjukkan bahwa nilai Chi Square $=15,826$ dengan tingkat signifikansi sebesar 11,07 demikian pula dengan nilai kelayakan yang lain yang belum memenuhi kriteria fit sehingga dapat disimpulkan bahwa terdapat perbedaan antara matriks kovarians sample dengan matriks kovarians populasi yang diestimasi diterima yang berarti model adalah belum fit. Sehingga secara keseluruhan model belum dapat diterima untuk memberikan konfirmasi yang cukup untuk dapat diterimanya hipotesis unidimensionalitas bahwa kelima indikator yang digunakan dapat mencerminkan variabel laten yang dianalisis yaitu variabel kinerja karyawan

\section{Pengujian Hipotesis}

Hasil analisis SEM dari penelitian ini dijabarkan dalam langkah pengujian hipotesis sebagai berikut:

\section{a. Pengujian Hipotesis 1}

$\mathrm{H}_{1}$ : Terdapat pengaruh antara kepuasan, komitmen dan motivasi terhadap $O C B$ Karyawan SPBU 4452212 Brebes.

Adapun hasil analisis SEM yang dilakukan diuraikan dalam gambar di bawah ini:

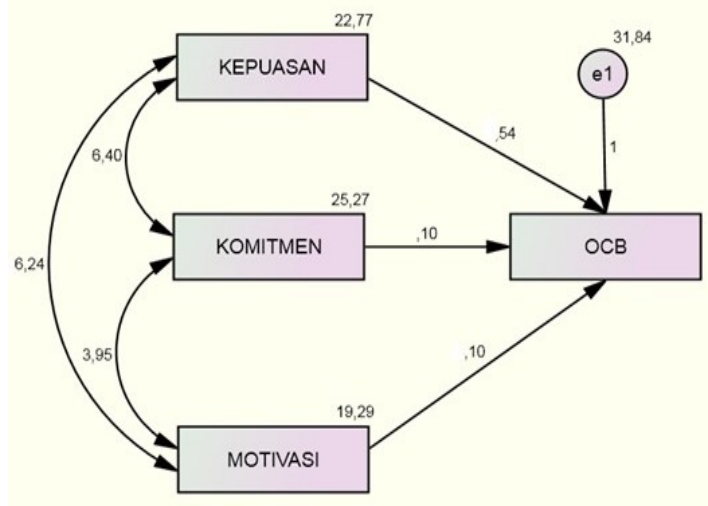

Gambar 7

Hasil Analisis Pengaruh Variabel Kepuasan, Komitmen dan Motivasi Terhadap Variabel $O C B$

Pada gambar di atas dapat dijelaskan bahwa nilai koefisien regresi terstandar (beta) kepuasan $\left(\mathrm{X}_{1}\right)$ terhadap $O C B$ (Y1) memperoleh nilai sebesar 0,54 , komitmen $\left(\mathrm{X}_{2}\right)$ terhadap $O C B(\mathrm{Y} 1)$ memperoleh nilai sebesar 0,10 , sedangkan motivasi (X3) terhadap $O C B(\mathrm{Y} 1)$ memperoleh nilai sebesar 0,10 . Dari nilai ketiga koefisien ini dapat disimpulkan bahwa variable kepuasan lebih penting dalam mempengaruhi $O C B$ disbandingkan dengan variabel komitmen dan motivasi.

Tabel 8

Variances: (Default model)

Pengaruh Variabel Kepuasan, Komitmen dan Motivasi Terhadap $O C B$

\begin{tabular}{|l|rllll|}
\hline & \multicolumn{1}{|c}{ Estimate } & S.E. & C.R. & P & Label \\
\hline KEPUASAN & 22,768 & 5,692 & 4,000 & $* * *$ & \\
KOMITMEN & 25,275 & 6,319 & 4,000 & $* * *$ & \\
MOTIVASI & 19,295 & 4,824 & 4,000 & $* * *$ & \\
e1 & 31,839 & 7,960 & 4,000 & $* * *$ & \\
\hline
\end{tabular}

Pada tabel diatas dapat dilihat hasil $\mathrm{p}$-value pada kolom $\mathrm{P}$ berupa tiga buah tanda asterisk $(* * *)$, yang berarti nilai p-value sanggat kecil $(<0,001)$, maka dengan demikian bahwa hipotesis yang menyatakan terdapat pengaruh antara Kepemimpinan, Motivasi Kerja 
dan Kompetensi terhadap Kepuasan Kerja Guru SMK. Muhammadiyah Bulakamba Kabupaten Brebes terbukti kebenaraanya.

\section{b. Pengujian Hipotesis 2}

$\mathrm{H}_{2}$ : Terdapat pengaruh antara kepuasan, komitmen dan motivasi terhadap Kinerja Karyawan SPBU 4452212 Brebes.

Adapun hasil analisis SEM yang dilakukan diuraikan dalam gambar di bawah ini:

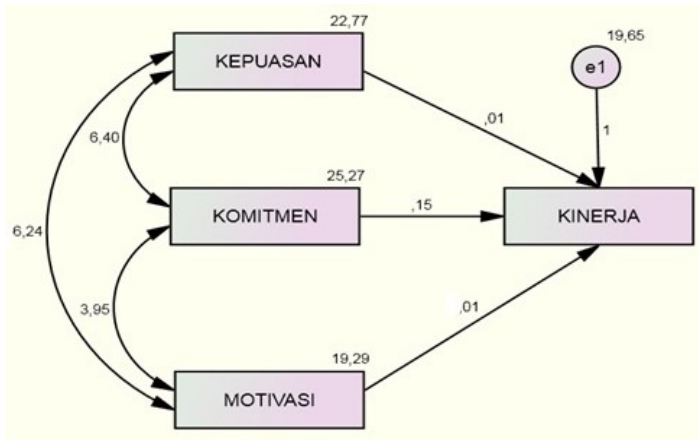

Gambar 8

Hasil Analisis Pengaruh Variabel Kepuasan, Komitmen dan Motivasi Terhadap Variabel Kinerja

Pada gambar di atas dapat dijelaskan bahwa nilai koefisien regresi terstandar (beta) kepuasan $\left(\mathrm{X}_{1}\right)$ terhadap kinerja (Y2) memperoleh nilai sebesar 0,01 , komitmen $\left(\mathrm{X}_{2}\right)$ terhadap kinerja (Y2) memperoleh nilai sebesar 0,15 , sedangkan motivasi (X3) terhadap kinerja (Y2) memperoleh nilai sebesar $0,01 .$. Dari nilai ketiga koefisien ini dapat disimpulkan bahwa variable komitmen lebih penting dalam mempengaruhi kinerja karyawan dibandingkan dengan variabel kepuasan dan motivasi.

Tabel 9

Variances: (Default model) Pengaruh Variabel Kepuasan, Komitmen dan Motivasi Terhadap Kinerja

\begin{tabular}{|l|rllll|}
\hline & \multicolumn{1}{|c}{ Estimate } & S.E. & C.R. & P & Label \\
\hline KEPUASAN & 22,768 & 5,692 & 4,000 & $* * *$ & \\
KOMITMEN & 25,275 & 6,319 & 4,000 & $* * *$ & \\
MOTIVASI & 19,295 & 4,824 & 4,000 & $* * *$ & \\
e1 & 19,649 & 4,912 & 4,000 & $* * *$ & \\
\hline
\end{tabular}

Pada tabel dapat dilihat hasil pvalue pada kolom $\mathrm{P}$ berupa tiga buah tanda asterisk $(* * *)$, yang berarti nilai $\mathrm{p}$ value sanggat kecil $(<0,001)$, maka dengan demikian bahwa hipotesis yang menyatakan terdapat pengaruh antara kepuasan, komitmen, dan motivasi terhadap karyawan SPBU 4452212 Brebes terbukti kebenaraanya.

\section{c. Pengujian Hipotesis 3}

$\mathrm{H}_{3:}$ Terdapat pengaruh antara $O C B$ terhadap kinerja karyawan SPBU 4452212 Brebes.

Adapun hasil analisis SEM yang dilakukan diuraikan dalam gambar di bawah ini:

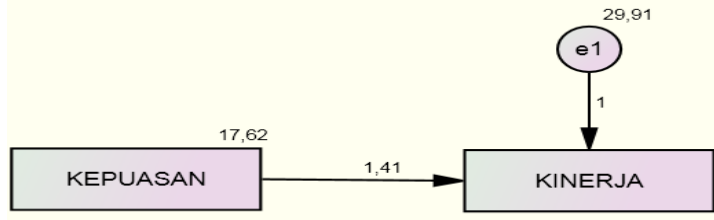

\section{Gambar 9}

Hasil Analisis Pengaruh Variabel Kepuasan Kerja terhadap Variabel Kinerja Karyawan

Pada gambar di atas dapat dijelaskan bahwa nilai koefisien regresi terstandar (beta) kepuasan kerja $\left(\mathrm{Y}_{1}\right)$ terhadap kinerja pegawai $\left(\mathrm{Y}_{2}\right)$ memperoleh nilai sebesar 0,07 . Tabel 10 Variances: (Default model)

Pengaruh Variabel $O C B$ Terhadap Kinerja

\begin{tabular}{|l|rrrrr|}
\hline & \multicolumn{1}{|c}{ Estimate } & S.E. & C.R. & P & Label \\
\hline$O C B$ & 37,500 & 9,375 & 4,000 & $* * *$ & \\
e1 & 20,102 & 5,026 & 4,000 & $* * *$ & \\
\hline
\end{tabular}

Pada tabel dapat dilihat hasil pvalue pada kolom $\mathrm{P}$ berupa tiga buah tanda asterisk $(* * *)$, yang berarti nilai $\mathrm{p}$ value sangat kecil $(<0,001)$, maka dengan demikian bahwa hipotesis yang menyatakan terdapat pengaruh antara kepuasan kerja terhadap kinerja 
karyawan SPBU 4452212 Brebes terbukti kebenaraanya.

\section{d. Pengujian Hipotesis 4}

$\mathrm{H}_{4}$ : Terdapat pengaruh antara Kepuasan, Komitmen dan Motivasi terhadap Kinerja Karyawan melalui $O C B$ Karyawan SPBU 4452212 Brebes .

Adapun hasil analisis SEM yang dilakukan diuraikan dalam gambar di bawah ini:

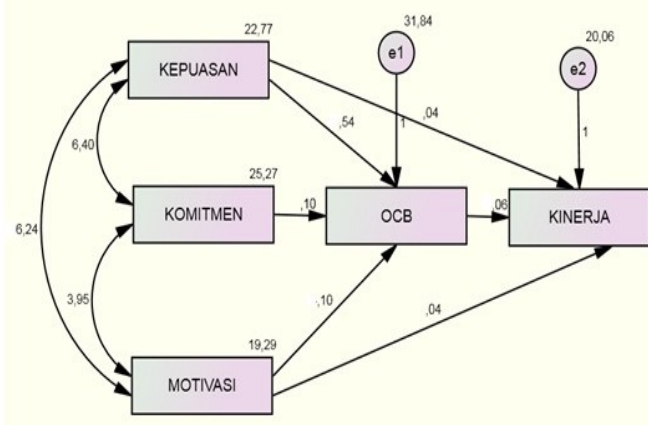

Gambar 10

Hasil Analisis Pengaruh Variabel Kepuasan, Komitmen dan Motivasi terhadap Variabel Kinerja Karyawan melalui $O C B$

Pada gambar di atas dapat dijelaskan bahwa nilai koefisien regresi terstandar (beta) Kepuasan $\left(\mathrm{X}_{1}\right)$, Komitmen $\left(\mathrm{X}_{2}\right)$ dan Motivasi (X3) terhadap Kinerja Karyawan $\left(\mathrm{Y}_{2}\right)$ melalui $O C B$ Karyawan (Y1) memperoleh nilai sebesar 1,03 .

Tabel 11

Variances: (Default model)

Pengaruh Variabel Kepuasan, Komitmen dan Motivasi terhadap Variabel Kinerja Karyawan melalui $O C B$

\begin{tabular}{|lrllll|}
\hline & Estimate & S.E. & C.R. & P & Label \\
\hline KEPUASAN & 22,768 & 5,692 & 4,000 & $* * *$ & \\
KOMITMEN & 25,275 & 6,319 & 4,000 & $* * *$ & \\
MOTIVASI & 19,295 & 4,824 & 4,000 & $* * *$ & \\
e1 & 31,839 & 7,960 & 4,000 & $* * *$ & \\
e2 & 20,062 & 5,015 & 4,000 & $* * *$ & \\
\hline
\end{tabular}

Pada tabel diatas dapat dilihat hasil p-value pada kolom $\mathrm{P}$ berupa tiga buah tanda asterisk $(* * *)$, yang berarti nilai p-value sanggat kecil $(<0,001)$, maka dengan demikian bahwa hipotesis yang menyatakan terdapat pengaruh antara Kepuasam, Komitmen dan Motivasi terhadap Kinerja Karyawan melalui $O C B$ Karyawan SPBU 4452212 Brebes terbukti kebenaraanya.

\section{SIMPULAN}

Setelah dilakukan hasil analisis dan pengujian terhadap hipotesis yang diujikan, maka diambil kesimpulan atas hipotesis-hipotesis tersebut. Berikut ini kesimpulan penelitian atas empat hipotesis penelitian yang digunakan.

1. Kepuasan menunjukkan kepuasan yang tinggi dilihat dari rata-rata indeks variabel kepuasan yakni sebesar 73,89\%. Komitmen karyawan SPBU 4452212 Brebes menunjukkan komitmen ang tinggi dilihat dari ratarata indeks variabel komitmen yakni sebesar 69,83\%. Motivasi karyawan SPBU 4452212 Brebes menunjukkan motivasi yang tinggi dilihat dari ratarata indeks variabel motivasi yakni sebesar 71,82\%. OCB karyawan SPBU 4452212 Brebes menunjukkan $O C B$ yang tinggi dilihat dari rata-rata indeks variabel $O C B$ yakni sebesar 79,21\%. Kinerja karyawan SPBU 4452212 Brebes menunjukkan kinerja yang tinggi dilihat dari rata-rata indeks variabel kinerja yakni sebesar $75,94 \%$.

2. Kepuasan kerja, komitmen organisasional, dan motivasi berpengaruh signifikan terhadap $O C B$ karyawan SPBU 4452212 Brebes. Hal tersebut dibuktikan dari nilai koefisien regresi terstandar (beta) Kepuasan $\left(\mathrm{X}_{1}\right)$ terhadap $O C B$ memperoleh nilai sebesar 0,54 , Komitmen $\left(\mathrm{X}_{2}\right)$ terhadap $O C B$ Karyawan memperoleh nilai sebesar 0,10 dan Motivasi $\left(\mathrm{X}_{3}\right)$ terhadap $O C B$ Karyawan memperoleh nilai sebesar 0,10 .

3. Kepuasan kerja, komitmen organisasional, dan motivasi berpengaruh 
signifikan terhadap kinerja karyawan SPBU 4452212 Brebes. Hal tersebut dibuktikan dari nilai koefisien regresi terstandar (beta) Kepuasan $\left(\mathrm{X}_{1}\right)$ terhadap Kinerja Karyawan memperoleh nilai sebesar 6,40. Komitmen $\left(\mathrm{X}_{2}\right)$ terhadap Kinerja Karyawan memperoleh nilai sebesar 3,95 dan Motivasi $\left(\mathrm{X}_{3}\right)$ terhadap Kinerja Karyawan memperoleh nilai sebesar 6,24.

4. Organizational Citizenship Behavior $(O C B)$ berpengaruh signifikan terhadap kinerja karyawan SPBU 4452212 Brebes. Hal tersebut dibuktikan dari hasil p-value berupa tiga buah tanda asterisk (***), yang berarti nilai p-value sangat kecil $(<0,001)$, maka dengan demikian bahwa hipotesis yang menyatakan terdapat pengaruh antara $O C B$ terhadap Kinerja Karyawan SPBU 4452212 Brebes terbukti kebenarannya.

5. Kepuasan kerja, komitmen organisasional dan motivasi berpengaruh signifikan terhadap kinerja melalui $O C B$ Karyawan SPBU 4452212 Brebes. Hal tersebut dibuktikan dari hasil p-value berupa tiga buah tanda asterisk $(* * *)$, yang berarti nilai $\mathrm{p}$ value sanggat kecil $(<0,001)$, maka dengan demikian bahwa hipotesis yang menyatakan terdapat pengaruh antara Kepuasan, Komitmen dan Motivasi terhadap Kinerja Karyawan melalui $O C B$ Karyawan SPBU 4452212 Brebes terbukti kebenarannya.

\section{SARAN}

\section{Manfaat Teoritis}

Implikasi teoritis penelitian ini adalah bahwa hasil penelitian ini berhasil membuktikan bahwa kepuasan, komitmen dan motivasi berpengaruh secara signifikan terhadap kepuasan karyawan.
Hasil penelitian ini juga berhasil membuktikan bahwa kepuasan, komitmen dan motivasi berpengaruh secara signifikan terhadap kinerja melalui $O C B$ Karyawan SPBU 4452212 Brebes.

Hasil penelitian ini sekaligus mendukung penelitian yang dilakukan oleh Windy Aprilia Murty dan Gunarsiti Hudiwinarsih (2012) yang membuktikan bahwa motivasi dan komitmen berpengaruh terhadap kinerja, penelitian yang dilakukan oleh Arum Darmawati, Lina Nur Hidayati dan Dyna Herlina S (2013) membuktikan bahwa kepuasan kerja berpengaruh signifikan terhadap kinerja, penelitian yang dilakukan Dewi Sandra (2008) membuktikan bahwa komitmen organisasional berpengaruh positif dan signifikan terhadap Organizational Citezenship Behavior (OCB).

\section{Manfaat Praktis}

Berdasarkan temuan pada penelitian ini maka beberapa implikasi kebijakan bagi SPBU 4452212 Brebes yang dapat diajukan dari penelitian ini adalah sebagai berikut:

1. Kepuasan karyawan dalam bekerja pada suatu organisasi akan berpengaruh pada kinerja karyawan. Dengan suasana kerja yang baik tidak hanya dapat memuaskan karaywan dalam melaksanakan tugas, tetapi juga berpengaruh dalam meningkatkan kinerja karyawan.

2. Komitmen kerja harus selalu ditumbuhkembangkan dalam organisasi. Dengan komitmen yang tinggi, setiap karyawan akan tahu apa tugasnya, bagaimana melakukannya, kapan pekerjaan dimulai dan kapan pekerjaan itu harus dselesaikan, seperti apa hasil kerja yang disyaratkan, dan kepada siapa ia mempertanggungjawabkan hasil pekerjaan itu. Dengan komitmen yang tinggi diharapkan akan dapat meningkatkan 
kinerja karyawan SPBU 4452212 Brebes

3. Karyawan SPBU 4452212 Brebes harus mempunyai motivasi kerja yang tinggi dalam melaksanakan tugas pokoknya dengan senantiasa menggunakan SOP (Standar Operasional Prosedur) yang sesuai ketentuan Instansi secara optimal. Sehingga akan mempercepat pencapain tujuan Instansi.

4. $O C B$ merupakan suatu perilaku karyawan untuk membantu karyawan lain dalam rangka untuk meningkat- kan kinerja karyawan. Dengan $O C B$ yang baik diharapkan tujuan organisasi akan cepat tercapai.

5. Kinerja yang sudah baik hendaknya dipertahankan dan ditingkatkan dengan jalan meningkatkan faktorfaktor yang mempengaruhi kinerja pegawai, selain keempat faktor tersebut, misalnya peningkatan kualitas pendidikan, pengetahuan, dan pengalaman yang dimiliki pegawai.

\section{DAFTAR PUSTAKA}

Allen, N.J. \& Meyer, J.P.199. "The Measurement and Antecendents of Affective, Continuance and Normative Commitment to Organizational Journal of Occuptional Psychology, Volume 63, pp.1-18

Ali, Fouzia, Monazza, Hafsa, Mehak, Asma, Mediha, Hina Saba. 2011. "The Effects of Jobs Stress and Job Performance on Employee's Commitment". European Journal of Scientific Research, Volume 60 No. 2. Pp 267-276

Arikunto, Suharsimi. 2009. Dasar-Dasar Evaluasi Pendidikan. Jakarta: Rineka Cipta.

Arikunto, Suharsimi. 2010. Prosedur Penelitian Pendekatan Praktek. Jakarta: Rineka Cipta.

Anyim dan Chidi. 2012. "Motivation and Employees Performance in Public and Private Sectors in nigeria. International Journal of Business administration. Volume. 3 No. 1 Januari 2012. Nigeria: University of lagos.

Daft,L, Richard. 2006. Management. Jakarta: Salemba Empat.

Edy. 2008. "Pengaruh Budaya Organisasi dan Lingkungan Kerja Terhadap Kinerja Karyawan Perawat Rumah Sakit Mata Dr. YAP Yogyakarta dengan Motivasi dan Kepuasan Kerja sebagai Variabel Mediasi”. Jurnal Ekonomi dan Bisnis. Volume 2 No.3 Hal. 59-174 Yogyakarta.

Gomes, Faustino Cordoso. 2005. Manajemen Sumber Daya Manusia. Yogyakarta: Andi Offset

Gunawan Imam. 2011. Organizational Citizenship Behavior Education Policy analysis archives, (Online), (http://masimangun.blogspot.com/2011/02/organization citizenship-behavior.html? $\mathrm{m}=1$, diakses 9 september 2016)

Griffin, R.W. (2004). "Management, 7th edition". Massachusetts: Houghton Mifflin Company. 
Handoko, T. Hani. 2003. Manajemen Personalia dan Sumber Daya Manusia. Yogyakarta: BPFE.

John, M.C., and taylor J.W. 1996. Leadership style, school climate and the Institutional commitment of teachers. International

Luthans,F. 2006. Perilaku organisasi. Yogyakarta: Andi.

Majorsy, Ursa. 2007. "Kepuasan Kerja, Semangat Kerja dan Komitmen Organisasional pada Staff Pengajar Universitas Gunadarma”. Jurnal Psikologi, Volume 1 No.1. Hal 64-74. Depok: Fakultas Psikologi Gunadarma.

Mangkunegara, A.P.2009. Manajemen Sumber daya Manusia Perusahaan. Bandung: PT. Remaja Rosdakarya.

Mathis L. Robert dan John Jackson.2006. Human Resource management. Jakarta: Salemba Empat.

Munandar, A.S.2011. Psikologi industri dan Organisasi. Jakarta: Universitas Indonesia Press.

Newstrom, J.W.2007 .Organizational Behavior: Human Behavior at work. New york: McGraw-hill.

Organ, D.W. \& Konovsky, M. 1989. Cognitive versus affective Determinants of Organizational Citizenship Behavior. Journal of Applied Psychology,Vol 74 no.1 hal. 157-164.

Organ, D.W., Podsakoff, P.M., \& Mackenzie, S.B. 2006. Organizational Citizenship Behavior Its Nature, antendents and Consquences. Sage Publication Offset.

Robbins,dan Judge,Thimoty.2007. Perilaku Organisasi. Jakarta: Salemba Empat.

Robbins, P.S. 2002. Prinsip-prinsip Perikau Organisasi. Jakarta: Erlangga.

Robbins dan Coulter. 2010. Manajemen. Jakarta: Erlangga.

Sunyoto Danang. 2012. Teori, Kuesioner dan analisis data Sumber Daya Manusia (praktik Penelitian). Yogyakarta: CAPS.

Singarimbun, Masri dan Sofyan Effendi. 2005. Metode Penelitian Survey. Jakarta: Pustaka LP3ES

Sugiyomo, 2010. Statistikuntuk Penelitian. Bandung: Alfa Beta.

Supranoto ,J.2003. Statistik Teori dan aplikasi. Jakarta. PT.Rineka Cipta.

Sopiah. 2008. Perilaku Organisasi. Yogyakarta: CV. Andi Offsett.

Terry, George R. 2009. Prinsip-Prinsip Manajemen. Jakarta: Bumi Aksara.

Wardani. 2009. "Pengaruh Kopensasi, Keahlian dan Motivasi Kerja terhadap Prestasi Kerja Karyawan pada PT. Pembangkitan Jawa Bali Unit Pembangkitan Muara Tawar". Muara Tawar: Universitas Gunadarma.

Wexley, K.N. Yukl, G.A. 2003. Perilaku Organisasi dan Psikologi Personalia. Jakarta: PT. Rineka Cipta. 